\title{
Robotics in
}

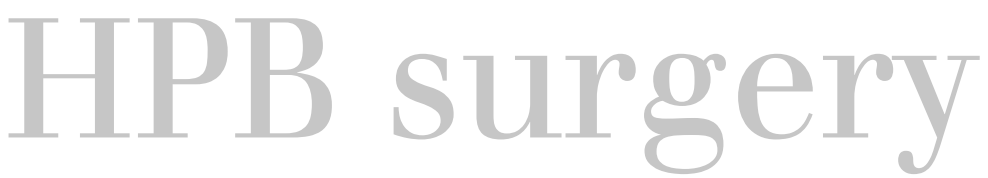

\section{Some major procedures and an assessment of their impact in the field}

Thomas Hanna Specialist Registrar, Department of HPB and Liver Transplant Surgery, The Royal Free NHS Trust, London

Charles Imber Consultant Surgeon, Department of HPB and Liver Transplant Surgery, The Royal Free NHS Trust, London

DOI: 10.1308/rcsann.supp1.31

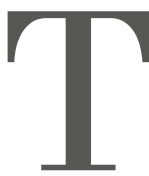
he majority of major HPB operations are still performed using an open large incisions contributing towards the morbidity of the procedure. The adoption of laparoscopic surgery has reduced the morbidity associated with large incisions in many different surgical specialties, but has had a relatively small impact on HPB surgery. The complex nature of this form of surgery, which demands fine manipulation of deep structures intimately related to major vessels, has appropriately resulted in a cautious and patchy adoption of the minimally invasive approach.

The inherent limitations of laparoscopic surgery, including rigid instruments and 2D vision, appear to prevent widespread adoption of this approach. Robotic surgery - with its well-described advantages over laparoscopic surgery, including 3D high-definition surgical vision, tremor filtration, motion-scaling, and an internal articulated endo-wrist ${ }^{1}$ - promises to overcome the technical limitations of laparoscopic surgery and may permit the minimally invasive approach to be extended to major HPB surgery.

Even if such techniques are shown to be feasible in high-volume enthusiastic centres, outcomes may not be reproducible in the wider HPB community; meticulous consideration must be given to safety, and oncological and economic factors before advocating widespread adoption. The ultimate test for such new technology is whether or not surgery performed robotically can prolong disease-specific survival in major HPB surgery. In pancreatic cancer, for example, shorter recovery times following robotic surgery may permit a greater proportion of patients to receive adjuvant chemotherapy within two months, and thus extend survival. In the treatment of colorectal liver metastasis, robotic surgery may permit a parenchymal-preserving strategy to be adopted more frequently, which again has the potential to improve disease-specific survival.

\section{Technique}

\section{Major liver resection}

For major liver resections, the patient 
is typically placed supine in a $15^{\circ}$ reverse Trendelenburg position, with a $30^{\circ}$ robotic camera placed to the right of the umbilicus for a right hepatectomy and to the left of the umbilicus for a left hepatectomy. Three robotic working ports and an assistant port are inserted as shown in Fig 1. Liver mobilisation is performed using an energy device and diathermy. Division of short hepatic veins during a right hepatectomy can be performed either using ligaclips or transfixion with 4-0 polypropylene suture. Hilar dissection is followed by division of the appropriate portal and arterial inflow vessels with Hem-o-lok clips or a vascular stapler device. The bile duct is usually divided during parenchymal transection. The transection plane is marked along the line of demarcation with diathermy. Division of the parenchyma is performed with a combination of Cavitron Ultrasonic Surgical Aspirator (CUSA), diathermy and energy device according to surgeon preference. The remaining hepatic vein is then divided with a vascular stapling device and over-sewn if required. The specimen is placed in a retrieval bag and, after undocking the robotic arms, removed via a Pfannenstiel incision.

\section{Pancreatic resection}

For a pancreatico-duodenectomy (PD), the patient is placed in a $15^{\circ}$ reverse Trendelenburg position, with a $30^{\circ}$ robotic camera to the left of the umbilicus, and three robotic ports and two assistant ports placed as shown in Fig 1(D). Complete mobilisation of the pancreas, including division of the gastro-colic ligament and kocherisation of the duodenum, is performed with diathermy and an energy device. Division of the stomach and jejunum is performed with an endo-GIA
Figure 1 (A-D) Port placement for (A) robotic right hepatectomy, (B) robotic left hepatectomy, (C) robotic distal pancreatectomy, and (D) robotic pancreatoduodenectomy. $\mathrm{C}=$ Camera port $12 \mathrm{~mm}, \mathrm{~A} 1=$ First assistant port $12 \mathrm{~mm}, \mathrm{~A} 2=$ Second assistant port $12 \mathrm{~mm}, \mathrm{R} 1-3=$ Robotic ports $8 \mathrm{~mm}$.

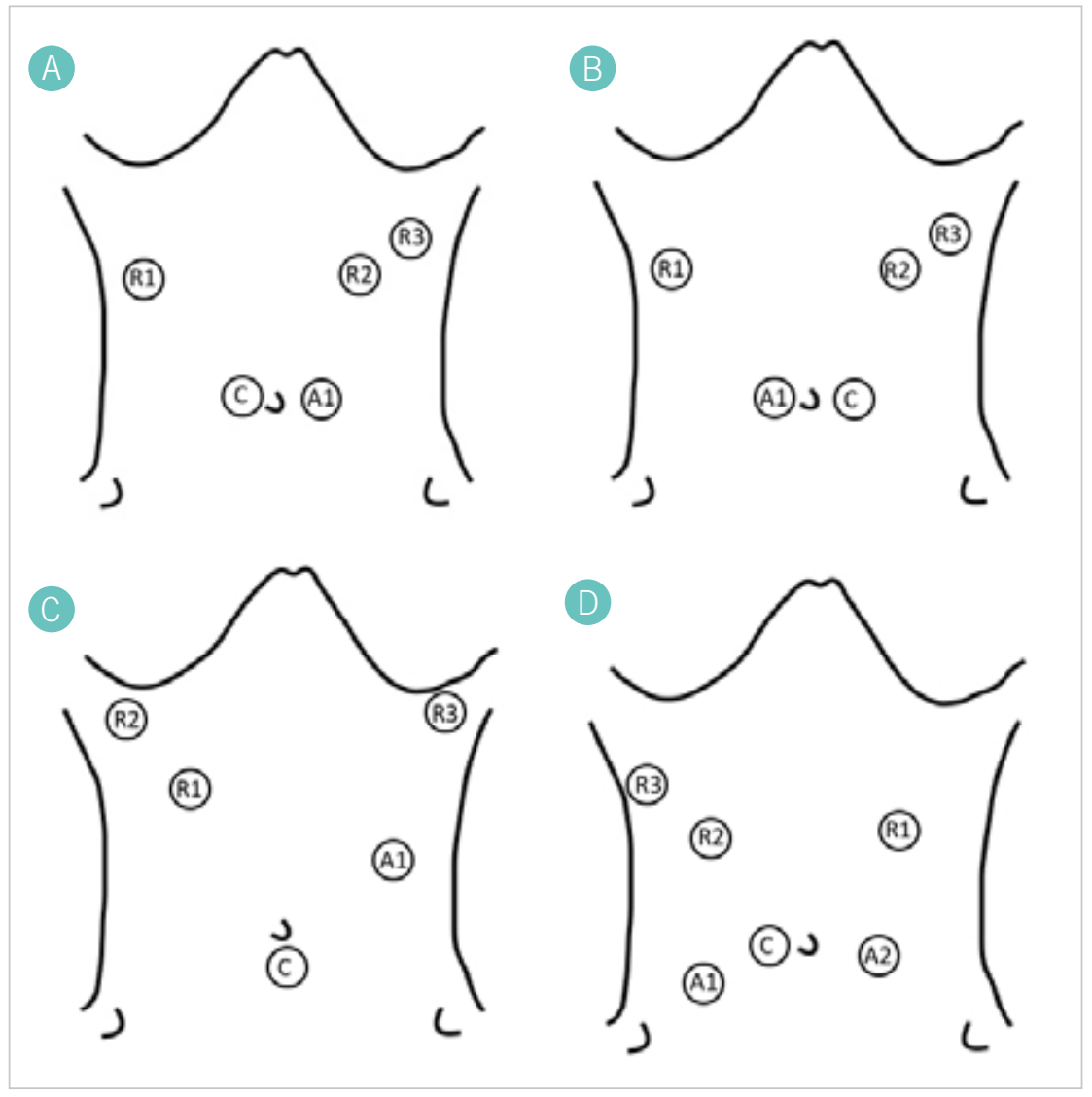

stapler, and the jejunal mesentery with an energy device. The gastro-duodenal artery is isolated and divided with Hem-o-lok clips or a vascular stapler. Following hilar dissection, the common hepatic duct is divided sharply. The pancreatic neck is then divided using an energy device, with sharp division of the pancreatic duct. The uncinate process is divided with an energy device and the specimen placed in a retrieval bag. There are a wide variety of reconstruction techniques that can nearly all be reproduced robotically.

For a distal pancreatectomy (DP), the patient is positioned in right semi-lateral position. Five ports are used: $38 \mathrm{~mm}$ robotic arms, a $12 \mathrm{~mm}$ camera port, and an assistant port Fig 1(C). After mobilisation of the pancreas, an endoscopic linear pancreas. A row of 3-0 Polypropylene sutures is sometimes placed over the end of the pancreas, according to surgeon preference. The remainder of the operation is similar to that of laparoscopic procedure.

\section{Pancreas surgery}

\section{Distal pancreatectomy (DP)}

DP intuitively lends itself to a minimally invasive approach because the procedure does not require a complex stapler is normally used to divide the 
Figure 2 Mobilising the pancreas from the splenic vein (SV) during a robotic DP. Figure reproduced from Oncotarget under a CC-BY 3.0 licence $^{5}$

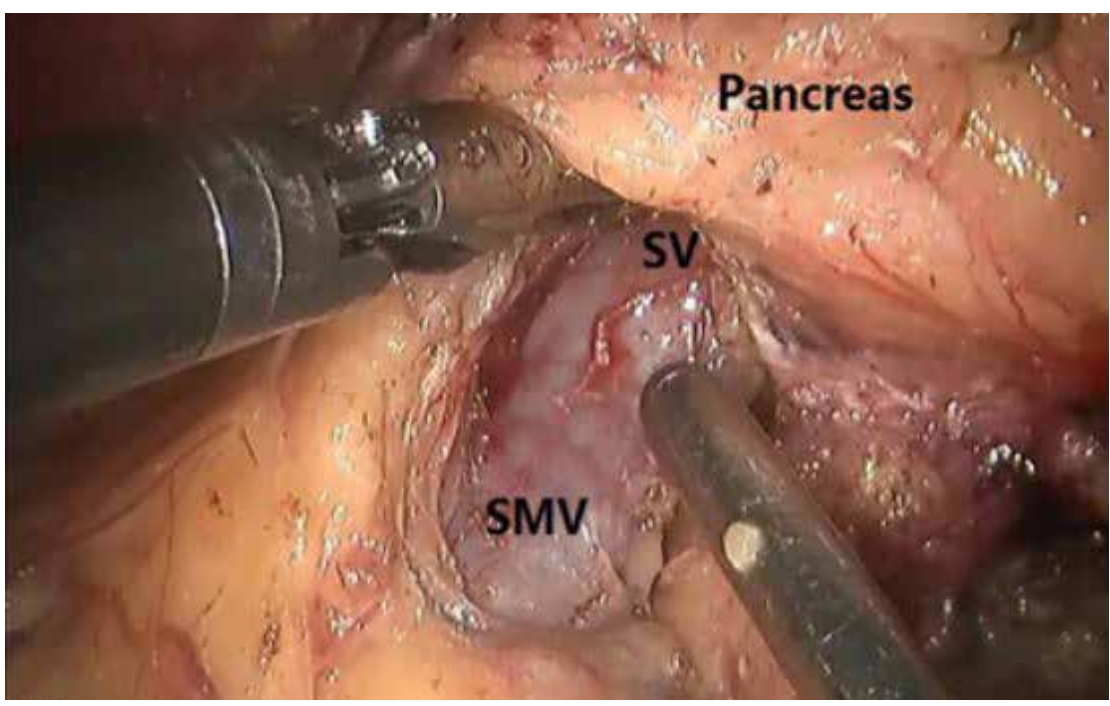

reconstruction. Furthermore, DP is an indication for patients with borderline malignant and benign tumours, in whom long-term survival is expected, and quality-of-life outcomes and the long-term immunological benefits of spleen preservation are emphasised. However, since the first laparoscopic DP (LDP) in 1996 , the approach has been tentatively adopted and currently accounts for only $12.6 \%$ of DPs performed. ${ }^{4}$

Spleen preservation during DP requires separation of the pancreatic parenchyma from the closely adhered splenic vein by division of small, fragile splenic tributary veins. This is a challenging step laparoscopically because tremor is amplified by long laparoscopic instruments fulcrumed over the abdominal wall port site. Traction injury causing even a small hole in the splenic vein typically results in significant bleeding, which obscures the view and often necessitates conversion both to open surgery and splenectomy. The improved ergonomics, tremor control and motion-scaling afforded by robotic surgery may overcome this technical pitfall to a certain extent (Fig 2).

Easy bleeding during traction of pancreas (due to the lack of haptic feedback characteristic of robotic surgery) has been described early in the learning curve. Reports suggest that this was more than compensated for by the increased visual feedback provided by magnified 3D vision ${ }^{6-8}$ overall, because it offered greater control of the splenic vein and its tributaries. dotal reports are now supported by the outcomes from non-randomised comparisons of robotic distal pancreatectomy (RDP) vs LDP. In a recent meta-analysis, ${ }^{9}$ splenic preservation rates were increased in RDP (106/198 [53.6\%] compared with LDP 76/281 [27.0\%]); $p<0.0001$.

Given that bleeding from the splenic vein is a frequent indication for both splenectomy and conversion to open surgery, it is not surprising that a lower rate of open conversion was also These early observations and anec- observed for RDP in these studies $19 / 230$ (8.2\%) for RDP and 109/503 (21.6\%) for LDP; $p=0.03 .{ }^{9}$ Daouadi et al also report an impressive 0\% conversion rate of RDP (0/30) compared with 15/94 (16\%) with LDP in a single-centre matched comparison. ${ }^{10}$ Lower conversion rates for RDP inevitably translate to other favourable outcomes such as reduced hospital length of stay (LOS) and, as a consequence, overall cost. Following the introduction of LDP, despite higher initial start-up costs, LDP was ultimately shown to be significantly less costly compared with ODP owing to a shorter LOS in the LDP group. ${ }^{11}$ Similarly, parallels may be drawn with RDP, which is reported to have a mean LOS of 7.18 days. This is significantly shorter than 9.08 days in the LDP group ( $p<0.001),{ }^{9}$ presumably owing to a lower rate of open conversion. One cost analysis study suggests that such a reduction was enough to entirely offset the high direct operative costs of robotic surgery. ${ }^{12}$ lelpo et al also demonstrated the same offsetting of high start-up costs associated with RDP as reduced LOS, as well as reduced use of surgical staplers and energy devices compared with LDP. ${ }^{13}$ However, other studies suggest RDP is considerably more costly than LDP, owing to start-up and maintenance costs - although there is wide variation in cost calculation methodology and assumptions. ${ }^{9}$

Kang et al provide a Korean perspective, reporting a 2.5-fold increase in costs with RDP compared with LDP. However, costs of the da Vinci ${ }^{\circledR}$ robot have reduced since this time and may no longer be an accurate reflection. ${ }^{14}$ Butturini ${ }^{15}$ estimated the cost of RDP at approximately twice that of LDP, purely owing to 'procedure-related' 
expenses, but failed to take into consideration differences in postoperative costs such as LOS. Furthermore, with robotic surgery increasingly being used by different specialties within hospitals, the amortised cost per case for robotic surgery is likely to fall further in the same way it has for laparoscopic surgery.

In addition to material costs and LOS, operating time is also a contributor to the overall cost. Most studies report a significantly longer operating time for RDP compared with LDP, , 12-14,16-18 which may in part be due to the 30 minutes required to dock and undock the robot, and in part due to the learning curve effect in RDP. In the largest series by Zureikat et al including 83 RDP, longer operating times are reported early in the series but eventually become equivalent to both the LDP and OPD series by the end of the 4-year experience. ${ }^{8}$ In 1 matched and LDP (233.2 $\min$ ); $p=0.17 .{ }^{9} \mathrm{~A}$ prospective health economic study is required to establish the true costs of RDP, which remain unclear.

Postoperative pancreatic fistula (PF) is described as the Achilles' heel of pancreatic surgery, representing the major procedure-related cause of morbidity and prolonged LOS. The rate of $\mathrm{PF}$ following $\mathrm{DP}$ is as high as $40 \%{ }^{19}$ when measured prospectively using the International Study Group of Pancreatic Fistula (ISGPF) definition. ${ }^{20}$ Retrospective case series comparisons have failed to demonstrate any significant difference in PF rates between LDP and ODP.10,12,14-18,21-24 Carochi et $a^{R 5}$ considered 5 non-randomised studies of RDP vs ODP including 155 patients, which also showed no difference in PF rate - this was later confirmed in a meta-analysis. ${ }^{9}$ Although disappointing, it is not an entirely surprising outcome

\section{Prolong disease-specific survival by increasing the proportion of patients going on to receive adjuvant therapy in a timely manner}

series of 30 RDP vs 94 LDP, shorter operating times were observed (293 min vs 372 min; $p<0.001$ ) despite the time needed for robot docking. The authors speculate that the increased dexterity and range of motion offered by RDP during the technically challenging steps of pancreas mobilisation and vascular control is responsible for the time-saving. ${ }^{10}$ However, the largest and most recent meta-analysis found no significant difference in operating time between RDP (262.8 min) because intuitively neither robotic nor laparoscopic surgery offers advantages over the open approach in terms of the ability to close the remnant pancreas.

\section{Pancreato-duodenectomy}

Laparoscopic pancreato-duodenectomy (LPD) was first described by Gagner and Pomp ${ }^{26}$ in 1994. In high-volume centres, LPD has been shown to be feasible, safe and have comparable surgical outcomes when compared with open pancreato-duodenectomy (OPD). ${ }^{27}$ Perhaps owing to the inherent limitations of laparoscopic surgery, LPD appears a viable approach in only a few specialist centres worldwide. Proponents for robotic surgery argue the technical advantages lend it to the complexity of a PD. ${ }^{28}$

The first robotic pancreato-duodenectomy (RPD) was performed in 2003 by Giulianotti et al, ${ }^{29}$ with the series later updated to 50 RPD.? In the same year in the US, Melvin and Needleman published a report of the robotic resection of a pancreatic neuroendocrine tumour. ${ }^{1}$ Currently, the largest series comes from Zureikat et al, ${ }^{8}$ with 132 RPDs. In this series of selected patients, a 90 -mortality of $3.8 \%$ was reported, which is well within the confidence limits of reported laparoscopic and open series. In terms of morbidity, the authors observed a significant decrease in major complications (Clavien-Dindo III-IV) in the last 40 cases - 27/88 (30\%) vs 6/44 (16\%); $p<0.05$ - suggesting the presence of a learning curve. In a large retrospective unmatched national cohort analysis of patients undergoing RPD (193) and LPD (235), the conversion rate was found to be lower $-11.4 \%$ vs $26.0 \%$ respectively; $p=0.004$ but no difference was seen between the approaches in adjusted overall complications. ${ }^{28}$ It is unlikely that randomised controlled trials assessing RPD will be feasible. Propensity-ranked comparisons of robotic, laparoscopic and open technologies from centres experienced in RDP are anticipated, and may be able to shed some light on the feasibility of RPD in terms of safety, oncology and cost, which at present are unclear. 
Robotic surgery has been described for the less common pancreatic resections, including median pancreatectomy ${ }^{5}$ and total pancreatectomy. ${ }^{28,5}$ Drawing conclusions beyond technical feasibility is not possible with such small numbers.

\section{Impact for pancreatic surgery}

The prospect of offering

minimally invasive surgery to patients undergoing PD is attractive, with the potential not only to reduce morbidity but also prolong disease-specific survival by increasing the proportion of patients going on to receive adjuvant therapy in a timely manner.

Although there is a competitive desire among surgeons and institutions to implement new minimally invasive techniques to improve patient outcomes, rapid introduction of novel techniques could have the opposite effect if premature. ${ }^{28}$ Even experienced centres have shown a higher rate of significant morbidity early in the series of RPD. Propensity-ranked comparisons of robotic, laparoscopic, and open approaches for RPD are eagerly awaited.

Robotic surgery promises to have a considerable impact for patients undergoing DP for benign and borderline malignant indications where spleen preservation is favoured. The higher spleen preservation and lower conversion-to-open rates provide tangible benefits to patients and may yet prove to be equivalent or cheaper in overall cost. In malignant indications, where en-bloc splenectomy is indicated, the benefits of RDP are less clear.

\section{Liver surgery}

Minimally invasive surgery of the liver is particularly challenging, owing to the organ's deep anatomical location, size, vascularity and intimate relation to major vascular structures. It can also be difficult to maintain a complete appreciation of the complex biliary and vascular network, and ligate fragile vessels during parenchymal division. The first use of laparoscopy for liver surgery was reported by Reick in $1991 .{ }^{30}$ Since then, as with most other surgical disciplines, several case-matched series have shown the laparoscopic approach to be feasible ${ }^{31}$ with advantages now familiar to laparoscopic surgery, including reduced blood loss, shorter LOS with comparable safety and oncological outcomes. ${ }^{32}$

Despite the feasibility of major (defined as three or more contiguous segments) laparoscopic hepatic resections in experienced high-volume centres, ${ }^{33}$ laparoscopic right and left hepatectomies account for only $9 \%$ and $7 \%$ of liver resections, respectively. The vast majority of laparoscopic liver surgery is accounted for by non-anatomical sectionectomies and left lateral resection (LLR). ${ }^{31}$ Arguably, patients undergoing major hepatectomies have the most to gain from the minimally invasive approach. The previously described advantages of robotic surgery may be suited to tackling these challenges, potentially extending the benefits of minimally invasive surgery to a higher proportion of patients undergoing liver resections. However, conclusive evidence of these benefits over open surgery from prospective randomised trials is lacking.

\section{Left lateral resection}

Resection of the left lateral section (Couinaud Segments II and II) is the simplest anatomic liver resection and the most conducive to minimally invasive surgery. The lobe is relatively easy to mobilise, does not have a close anatomical relationship with major vascular structures, and does not routinely require hilar dissection, which can be tedious and time-consuming using a minimally invasive approach. Laparoscopic surgery has become the standard practice for LLR, ${ }^{34,35}$ despite inconclusive results from the only randomised controlled trial (ORANGE II) that compared open LLR (O-LLR) with laparoscopic LLR (L-LLR). ${ }^{36}$ The study failed to recruit, partly owing to an absence of surgical equipoise reflected in a consensus statement by the International Consensus Conference for laparoscopic liver resections that L-LLR should be considered standard practice. ${ }^{34}$

Three non-matched retrospective studies ${ }^{37-39}$ and a propensity score-matched cohort study ${ }^{40}$ have compared robotic LLR (R-LLR) with L-LLR. The robotic approach has not emerged from these studies as showing any additional benefits over L-LLR. Packiam et al found R-LLR gave inferior clinical outcomes and increased cost compared with L-LLR. ${ }^{39} \mathrm{Kim}$ et al reported equivalence in outcomes but longer operating time with R-LLR (403.8 mins) compared with L-LLR (245.9 mins); $p<0.001 .38$ In a small retrospective comparison of heterogeneous groups, Lee et al reported comparable outcomes between R-LLR and L-LLR. ${ }^{37}$ Finally, Salloum et al reported comparable outcomes between the two groups, but after propensity score-matching, R-LLR had a longer operating time (203 mins) than L-LLR (140 mins); $p=0.02$. 
Non-anatomical sectionectomies The International Position on Laparoscopic Liver Surgery, Louisville statement ${ }^{35}$ identified favourable indications for laparoscopic resection as solitary lesions that are $5 \mathrm{~cm}$ or less and located in the peripheral Segments II-VI. Within these parameters, laparoscopic surgery is a widely accepted approach. Kingman et al compared robotic ( $n=64$ ) with open ( $n=64$ ) liver resections matched for indication and number of segments. The majority of resections were for single-segment resections. The
Several groups have reported that robotic resection of the P-S segments is technically easier than with laparoscopic surgery. ${ }^{41-45}$ Trosis et al compared unmatched liver resections performed laparoscopically (223) vs robotically (40) from two institutions. Robotic surgery permitted a higher rate of parenchymal-preserving surgery to be performed, both overall (37\% vs $16.1 \%$ ) and considering only P-S segments (55\% vs $34.1 \%$; $p=0.019) .{ }^{42}$ The strategy of conservative, parenchymal-sparing but oncologically effective liver resection

\section{Several groups have reported that robotic resection of the $P$-S segments is technically easier than with laparoscopic surgery}

authors demonstrated less blood loss (100ml vs 300ml; $p<0.001$ ), shorter LOS and, interestingly, a shorter operating time (163 min vs 210 min; $p=0.017$ ) respectively, with comparable safety parameters. ${ }^{41}$ As with L-LLR, the use of robotic surgery may struggle to demonstrate clear benefits of its laparoscopic counterpart.

However, laparoscopic surgery is not well-suited to resection of the superior-posterior (S-P) Sections IVa, VII and VIII. First, access is difficult as rigid laparoscopic instruments are fulcrumed against the costal margin. Second, the delicate hepatocaval dissection required during mobilisation of the right hemi-liver risks major uncontrolled bleeding. Both these issues can, to some extent, be overcome by endo-wristed movements and tremor filtration of the robot, respectively. for colorectal liver metastasis in combination with chemotherapy has been shown to improve overall survival rates, ${ }^{46,47}$ thus robotic surgery has the potential to improve disease-specific overall survival. The results from the $\mathrm{P}$-S liver segment resection randomised controlled trial (ORANGE SEGMENTS trial) are awaited; however, robotic surgery may yet become established as the preferred minimally invasive approach.

\section{Major hepatectomy}

Results from randomised trials comparing laparoscopic vs open for hemi-hepatectomies (ORANGE-II PLUS) are awaited. Occun et $a^{48}$ provide a valuable review of the 14 major series (9 or more patients) of robotic liver surgery up until 2015, including all types of liver resections (major and minor) 2,39,42-44,49-57 - the big- gest, with 70 robotic liver resections, coming from Giulianotti et al. ${ }^{43}$ Since this review, a further 6 series have been published, ${ }^{41,45,58-61}$ totalling 627 patients of which 145 (23.1\%) were for major liver resections. Some of these studies were matched with laparoscopic surgery $39,42,44,49,50,53,56,57,59-61$ and have shown generally comparable outcomes for blood loss, LOS, $\mathrm{R}^{0}$ rate, operation time, morbidity and mortality.

Spampinato et al directly compared 25 patients undergoing laparoscopic major hepatecotomy (LMH) with 25 patients undergoing robotic major hepatectomy $(\mathrm{RMH})$ in a multicentre retrospective comparison. There was no difference between the groups in terms of complications, conversion-to-open rate (4\%), operative time, estimated blood loss or LOS. The LMH group had quicker recovery of bowel activity, with shorter time to first flatus ( 1 vs 3 days; $p=0.023$ ). The International Consensus Conference for Laparoscopic Surgery considers robotic liver surgery to be early in the development stage (IDEAL Stage 2a), and advises cautious implementation with evaluation using a prospective registry. ${ }^{34}$ Reported advantages of the robotic approach include isolating and dividing the appropriate portal and arterial vascular branches in the hilum, which has been perceived as easier and safer than laparoscopical$\mathrm{ly}^{43}$ - particularly in the presence of aberrant anatomy. However, others argue that such subjective technical improvements offered by the robotic approach are unlikely to translate into improved clinical outcomes for the patient. ${ }^{41}$

\section{Conclusion}

Laparoscopic liver surgery has 
become an established technique for LLR and non-anatomical resections from Segments II-VI, despite lack of evidence from prospective randomised controlled trials. In these procedures, robotic surgery may only be able to offer the additional benefit of completing the surgery in purely minimally invasive fashion. Countered with the increased cost and operating time associated with robotic surgery, its role in this instance should be questioned. Laparoscopic surgery for major hepatectomies is currently under evaluation in ongoing randomised controlled trials, and its superiority over open resection has not been ascertained. Whether robotic surgery for major hepatectomies, therefore, should be measured against the 'gold standard' of laparoscopic or open surgery is debatable until the results of ongoing randomised controlled trials are available. Although certain steps in the procedure such as hepatocaval and portal dissection may well be easier with the robotic approach compared with the laparoscopic approach, whether this translates into clinically important improvements outcomes remains to be seen. Non-anatomical resections from superior posterior sections of the liver have much to gain from a minimally invasive approach but are particularly challenging with a laparoscopic approach. Anecdotal evidence suggests that robotic surgery may have meaningful advantages over laparoscopic surgery - in this particular instance, permitting a purely minimally invasive parenchymal-preserving resection.

\section{References}

1. Melvin WS, Needleman BJ, Krause KR, Ellison EC. Robotic resection of pancreatic neuroendocrine tumor. J Laparoendosc Adv
Surg Tech 2003; 13(1): 33-36.

2. Choi GH, Choi SH, Kim SH et al. Robotic liver resection: Technique and results of 30 consecutive procedures. Surg Endosc Other Interv Tech 2012; 26(8): 2,247-2,258.

3. Sussman LA, Christie R, Whittle DE. Laparoscopic excision of distal pancreas including insulinoma. Aust N Z J Surg 1996; 66(6): 414-416.

4. Sulpice L, Farges O, Goutte N et al. Laparoscopic distal pancreatectomy for pancreatic ductal adenocarcinoma. Ann Surg 2015; 262(5): 868-874.

5. Zhang J, Jin J, Chen S et al. Minimally invasive distal pancreatectomy for PNETs: laparoscopic or robotic approach? Oncotarget [Internet]. 2017; 8(20): 33872-83. www. impactjournals.com/oncotarget (cited March 2018).

6. Kim DH, Kang CM, Lee WJ, Chi HS. The first experience of robot assisted spleen-preserving laparoscopic distal pancreatectomy in Korea. Yonsei Med J 2011; 52(3): 539-542.

7. Giulianotti PC, Sbrana F, Bianco FM et al. Robot-assisted laparoscopic pancreatic surgery: Single-surgeon experience. Surg Endosc Other Interv Tech 2010; 24(7): 1,646-1,657.

8. Zureikat AH, Moser AJ, Boone BA et al. 250 Robotic pancreatic resections safety and feasibility. Ann Surg 2013; 258(4): 554-559.

9. Guerrini GP, Lauretta A, Belluco C et al. Robotic vs laparoscopic distal pancreatectomy: An up-to-date metaanalysis. BMC Surg 2017; 17(1): 1-11.

10. Daouadi M, Zureikat AH, Zenati MS et al. Robot-assisted minimally invasive distal pancreatectomy is superior to the laparoscopic technique. Ann Surg 2013; 257(1): 128-132.

11. Rutz DR, Squires MH, Maithel SK et al. Cost comparison analysis of open vs laparoscopic distal pancreatectomy. Hpb 2014; 16(10): 907-914.

12. Waters JA, Canal DF, Wiebke EA et al. Robotic distal pancreatectomy: Cost effective? Surgery [Internet] 2010; 148(4): 814-823. http: //dx.doi.org/10.1016/j.surg.2010.07.027 (cited March 2018).

13. Ielpo B, Duran H, Diaz E et al. Robotic vs laparoscopic distal pancreatectomy: A comparative study of clinical outcomes and costs analysis. Int J Surg [Internet] 2017; 48: 300-304. https: //doi.org/10.1016/j. ijsu.2017.10.075 (cited March 2018).
14. Kang CM, Kim DH, Lee WJ, Chi HS. Conventional laparoscopic and robot-assisted spleen-preserving pancreatectomy: Does da Vinci have clinical advantages? Surg Endosc Other Interv Tech 2011; 25(6): 2,004-2,009.

15. Butturini G, Damoli I, Crepaz L et al. A prospective non-randomised single-center study comparing laparoscopic and robotic distal pancreatectomy. Surg Endosc Other Interv Tech 2015; 29(11): 3,163-3,170.

16. Goh BKP, Chan CY, Soh H-L, Lee SY et al. A comparison between robotic-assisted laparoscopic distal pancreatectomy vs laparoscopic distal pancreatectomy. Int J Med Robot Comput Assist Surg 2017; 13(1): e1733. http: //doi.wiley.com/10.1002/ rcs.1733 (cited March 2018).

17. Lai ECH, Tang CN. Robotic distal pancreatectomy vs conventional laparoscopic distal pancreatectomy: a comparative study for short-term outcomes. Front Med 2015; 9(3): 356-360.

18. Lee SY, Allen PJ, Sadot E et al. Distal pancreatectomy: A single institution's experience in open, laparoscopic, and robotic approaches. J Am Coll Surg [Internet] 2015; 220(1): 18-27. http: //dx.doi.org/10.1016/j. jamcollsurg.2014.10.004 (cited March 2018).

19. Diener MK, Seiler CM et al. Efficacy of stapler vs hand-sewn closure after distal pancreatectomy (DISPACT): A randomised, controlled multicentre trial. Lancet 2011; 377: 1,514-1,522.

20. Pulvirenti A, Ramera M, Bassi C. Modifications in the International Study Group for Pancreatic Surgery (ISGPS) definition of postoperative pancreatic fistula. Trans/ Gastroenterol Hepatol 2017; 2

21. Venkat R, Edil BH, Schulick RD, Lidor AO, Makary MA, Wolfgang CL. Laparoscopic distal pancreatectomy is associated with significantly less overall morbidity compared to the open technique: A systematic review and meta-analysis. Ann Surg 2012; 255(6): 1,048-1,059.

22. Balzano G, Bissolati M, Boggi U et al. A multicenter survey on distal pancreatectomy in Italy: results of minimally invasive technique and variability of perioperative pathways. Updates Surg 2014; 66(4): 253-263.

23. Chen S, Zhan Q, Chen J zhi et al. Robotic approach improves spleen-preserving rate and shortens postoperative hospital stay of laparoscopic distal pancreatectomy: a 
matched cohort study. Surg Endosc Other Interv Tech 2015; 29(12): 3,507-3,518.

24. Moustris GP, Hiridis SC, Deliparaschos KM, Konstantinidis KM. Evolution of autnomous and semi-autonomous robotic surgical systems: a review of the literature. Int J Med Robot 2011; 7(April): 375-392.

25. Cirocchi R, Partelli S, Coratti A, Desiderio J, Parisi A, Falconi M. Current status of robotic distal pancreatectomy: A systematic review. Surg Oncol 2013; 22(3): 201-207. http: // dx.doi.org/10.1016/j.suronc.2013.07.002 (cited March 2018).

26. Gagner M, Pomp A. Laparoscopic pyloruspreserving pancreatoduodenectomy. Surgical Endoscopy 1994; (April 1993): 408-410.

27. Asbun HJ, Stauffer JA. Laparoscopic vs open pancreaticoduodenectomy: Overall outcomes and severity of complications using the accordion severity grading system. J Am Coll Surg 2012; 215(6): 810-819. http: //dx.doi.org/10.1016/j. jamcollsurg.2012.08.006 (cited March 2018).

28. Nassour I, Wang SC, Porembka MR et al. Robotic vs laparoscopic pancreaticoduodenectomy: a NSQIP analysis. J Gastrointest Surg 2017; 21(11): 1,784-1,792.

29. Giulianotti PC, Coratti A, Angelini M et al. Robotics in general surgery. JAMA Surg 2003; 138(July): 777-784.

30. Reich H, McGlynn F, DeCaprio J, Budin R. Laparoscopic excisions of benign liver lesions. Obstet Gynecol 1991; 78: 1,991.

31. Nguyen KT, Gamblin TC, Geller DA. World review of laparoscopic liver resection-2,804 patients. Ann Surg 2009; 250(5): 831-841.

32. Rao A, Rao G, Ahmed I. Laparoscopic left lateral liver resection should be a standard operation. Surg Endosc Other Interv Tech 2011; 25(5): 1,603-1,610.

33. Wang X, Hu M, Zhao Z et al. An improved surgical technique for pure laparoscopic left hemihepatectomy: Ten years experience in a tertiary center. J Laparoendosc Adv Surg Tech [Internet] 2016; 26(11): 862-869. http: //online.liebertpub.com/doi/10.1089/ lap.2016.0047 (cited March 2018).

34. Wakabayashi G, Cherqui D, Geller DA et al. Recommendations for laparoscopic liver resection: A report from the second international consensus conference held in morioka. Ann Surg 2015; 261: 4.

35. Buell JF, Cherqui D, Geller DA et al. The international position on laparoscopic liver surgery. Ann Surg 2009; 250(5): 825-830.

36. Wong-Lun-Hing EM, van Dam RM, van Breukelen GJP et al. Randomized clinical trial of open vs laparoscopic left lateral hepatic sectionectomy within an enhanced recovery after surgery programme (ORANGE II study). Br J Surg [Internet] 2017; 104(5): 525-535. http://doi.wiley.com/10.1002/bjs.10438 (cited March 2018).

37. Lee K-F, Cheung Y-S, Chong CCN et al. Laparoscopic and robotic hepatectomy: experience from a single centre. ANZ J Surg [Internet] 2016; 86(3): 122-126. http://doi. wiley.com/10.1111/ans.13339 (cited March 2018).

38. Kim JK, Park JS, Han DH et al. Robotic vs laparoscopic left lateral sectionectomy of liver. Surg Endosc Other Interv Tech 2016; 30(11): 4,756-4,764.

39. Packiam V, Bartlett DL, Tohme S et al. Minimally invasive liver resection: robotic vs laparoscopic left lateral sectionectomy. J Gastrointest Surg 2012; 16(12): 2,2332,238.

40. Salloum C, Lim C, Lahat E et al. Roboticassisted $v s$ laparoscopic left lateral sectionectomy: analysis of surgical outcomes and costs by a propensity score matched cohort study. World J Surg 2017; 41(2): 516-524.

41. Kingham TP, Leung U, Kuk D et al. Robotic liver resection: A case-matched comparison. World J Surg 2016; 40(6): 1,422-428.

42. Troisi RI, Patriti A, Montalti R, Casciola L. Robot assistance in liver surgery: a real advantage over a fully laparoscopic approach? Results of a comparative biinstitutional analysis. Int J Med Robot 2013; 9: 160-166.

43. Giulianotti PC, Coratti A, Sbrana F et al. Robotic liver surgery: Results for 70 resections. Surgery [Internet] 2011; 149(1): 29-39. http://dx.doi.org/10.1016/j. surg.2010.04.002 (cited March 2018).

44. Tranchart H, Ceribelli C, Ferretti S et al. Traditional vs robot-assisted full laparoscopic liver resection: a matched-pair comparative study. World J Surg 2014; 38(11): 2,9042,909.

45. Nota CLMA, Molenaar IQ, van Hillegersberg $\mathrm{R}$ et al. Robotic liver resection including the posterosuperior segments: initial experience. J Surg Res [Internet] 2016; 206(1): 133-138. http://dx.doi.org/10.1016/j. jss.2016.06.079 (cited March 2018). 46. Gold JS, Are C, Kornprat P et al. Increased use of parenchymal-sparing surgery for bilateral liver metastases from colorectal cancer is associated with improved mortality without change in oncologic outcome: Trends in treatment over time in 440 patients. Ann Surg 2008; 247: 109-117.

47. Alvarez FA, Claria SR, Oggero S, Santibañes $\mathrm{E}$ de. Parenchymal-sparing liver surgery in patients with colorectal carcinoma liver metastases. World J Gastrointest Surg 2016; 8: 407-423.

48. Ocuin LM, Tsung A. Robotic liver resection for malignancy: Current status, oncologic outcomes, comparison to laparoscopy, and future applications. J Surg Oncol 2015; 112(3): 295-301.

49. Tsung A, Geller DA, Sukato DC et al. Robotic vs laparoscopic hepatectomy: A matched comparison. Ann Surg 2014; 259(3): 549-555.

50. Wu YM, Hu RH, Lai HS, Lee PH. Roboticassisted minimally invasive liver resection. Asian J Surg [Internet] 2014; 37(2): 53-57. http://dx.doi.org/10.1016/j. asjsur.2014.01.015 (cited March 2018).

51. Lai ECH, Yang GPC, Tang CN. Robot-assisted laparoscopic liver resection for hepatocellular carcinoma: Short-term outcome. Am J Surg [Internet] 2013; 205(6): 697-702. http:// dx.doi.org/10.1016/j.amjsurg.2012.08.015 (cited March 2018).

52. Chan OCY, Tang CN, Lai ECH et al. Robotic hepatobiliary and pancreatic surgery: a cohort study. J Hepatobiliary Pancreat Sci [Internet] 2011; 18(4): 471-480. http:// doi.wiley.com/10.1007/s00534-011-0389-2 (cited March 2018).

53. Spampinato MG, Coratti A, Bianco L et al. Perioperative outcomes of laparoscopic and robot-assisted major hepatectomies: an Italian multi-institutional comparative study. Surg Endosc Other Interv Tech 2014; 28(10): 2,973-2,979.

54. Casciola L, Patriti A, Ceccarelli G et al. Robot-assisted parenchymal-sparing liver surgery including lesions located in the posterosuperior segments. Surg Endosc Other Interv Tech 2011; 25(12): 3,8153,224.

55. Ji W Bin, Wang HG, Zhao ZM et al. Roboticassisted laparoscopic anatomic hepatectomy in China: Initial experience. Ann Surg 2011; 253(2): 342-348.

56. Yu Y-D, Kim K-H, Jung D-H et al. Robotic vs laparoscopic liver resection: a comparative study from a single center. Langenbeck's 
Arch Surg [Internet] 2014; 399(8): 1,039-

1,045. http://link.springer.com/10.1007/

s00423-014-1238-y (cited March 2018).

57. Berber E, Akyildiz HY, Aucejo F et al. Robotic vs laparoscopic resection of liver tumours. HPB (Oxford) [Internet] 2010; 12(8):

583-586. http://dx.doi.org/10.1111/j.14772574.2010.00234.x (cited March 2018).

58. Felli E, Santoro R, Colasanti M et al. Robotic liver surgery: preliminary experience in a tertiary hepato-biliary unit. Updates Surg [Internet] 2015; 67(1): 27-32. http://dx.doi. org/10.1007/s13304-015-0285-4 (cited March 2018).

59. Montalti R, Scuderi V, Patriti A et al. Robotic vs laparoscopic resections of posterosuperior segments of the liver: a propensity scorematched comparison. Surg Endosc Other Interv Tech 2016; 30(3): 1,004-1,013.

60. Croner RS, Perrakis A, Hohenberger W, Brunner M. Robotic liver surgery for minor hepatic resections: a comparison with laparoscopic and open standard procedures. Langenbeck's Arch Surg 2016; 401(5): 707-714.

61. O'Connor VV, Vuong B, Yang S, Fronzo ADI. Robotic Minor Hepatectomy Offers a Favorable Learning Curve and May Result in Superior Perioperative Outcomes Compared with Laparoscopic Approach. Am Surg 2017; 83: 1,085-1,088. 